\title{
The Role of Sickness in the Evaluation of Job Search Assistance and Sanctions
}

\author{
Gerard J. van den Berg* \\ Barbara Hofmann ${ }^{\dagger}$ \\ Arne Uhlendorff ${ }^{\ddagger}$ \\ preliminary and incomplete
}

April 10, 2013

\begin{abstract}
Unemployment insurance agencies often combat moral hazard by punishing refusals to apply to assigned vacancies. However, the possibility to report sick creates an additional moral hazard, since (at least in Germany) during sickness spells, minimum requirements on search behavior do not apply. We analyze the effects on unemployment duration and job quality, as measured by the wage and employment stability. To evaluate sanction effects and the impact of receiving vacancy referrals, we take the endogenous probability of reporting sick into account. We estimate multi-spell duration models with selection on unobserved characteristics. We find that vacancy referrals and imposed sanctions increase the exit rate to work. Jobs found after receiving a vacancy referral as well as after the imposition of a sanction are less stable and go along with a lower wage. Our results suggest that around $8.5 \%$ of sickness absence during unemployment are induced by receiving a vacancy referral. The impact of vacancy referrals on sickness absence is decreasing over time spent in unemployment.
\end{abstract}

Keywords: unemployment, vacancy referrals, sanctions, sickness absence, moral hazard.

JEL codes: J64, J65, C41, C21

\footnotetext{
*University of Mannheim, IFAU Uppsala, VU University Amsterdam, IZA Bonn

$\dagger$ University of Mannheim, IAB Nuremberg

$\ddagger$ University of Mannheim, IAB Nuremberg, DIW Berlin, IZA Bonn
}

We thank John Ham, Bo Honore, Per Johannson, Johan Vikström, Nikolas Ziebarth and seminar participants at CREST, University of Dortmund, University of Munich, NIW in Hannover, and at several workshops and conferences for valuable comments. 


\section{Introduction}

Job vacancy referrals are an important policy measure to assist unemployed job seekers in searching for a job and to monitor their job search behavior. Refusing to apply to assigned vacancies can lead to a sanction. By setting an incentive to comply with the job search requirements and to apply to assigned vacancies, the intention is to combat moral hazard and to increase the transition probability from unemployment to work. However, individuals may try to avoid an application to an assigned vacancy and the risk of being sanctioned, respectively, and thereby may undermine the incentive setting. In the German system, the possibility to report sick creates an additional moral hazard, since during sickness spells minimum requirements on search behavior do not apply and therefore unemployed individuals cannot be sanctioned. In this paper, we analyze the effects of vacancy referrals and sanctions on the unemployment duration and the quality of job matches, taking the endogenous probability of reporting sick into account.

A number of studies show that monitoring and job search assistance have an impact on the job search behavior of unemployed workers. For example, Graversen and van Ours (2008) provide evidence that participation in a mandatory activation program reduces individual unemployment duration. Engström, Hesselius, and Holmlund (2012) find that an intensified monitoring of job search behavior after receiving a vacancy referral increases the probability of job application, and van den Berg and van der Klaauw (2006) provide evidence that monitoring causes a shift from informal to formal job search. Studies on the impact of imposed sanctions on unemployment duration usually find an increased exit rate to work after a sanction, see e.g. van den Berg, van der Klaauw, and van Ours (2004), Lalive, van Ours, and Zweimüller (2005), and van der Klaauw and van Ours (2012). Recent studies additionally take the effects of sanctions on post-unemployment outcomes into account; van den Berg and Vikstroem (2012) find a negative impact of sanctions on job quality, measured by hourly wages and the occupational level, and Arni, Lalive, and van Ours (2012) find evidence for negative effects on earnings and employment stability.

The literature on moral hazard in sickness absence suggests that the variation of sickness absence of employed workers across time and place can be partly explained by sickness insurance institutions and cyclical fluctuations, see e.g. Ruhm (2000), Ichino and Riphahn (2005), Ziebarth and Karlsson (2010) and Markussen, Roed, Rogeberg, and Gaure (2011). Only a few studies analyze the determinants of sickness absence among unemployed individuals. Based on Swedish data Larsson (2006) and Hall and Hartman (2010) analyze the use of sickness insurance and unemployment 
insurance. Both studies report a positive impact of the generosity of sickness benefits on the probability of reporting sick, and Larsson (2006) additionally finds that sick reports increase as the unemployment benefits expiration date approaches. In line with this Henningsen (2008) presents evidence that the transition rate to sickness insurance increases sharply shortly before the exhaustion of unemployment benefits among Norwegian unemployed. Using data for Germany, Hofmann (2010) presents evidence for an increased transition rate into sickness absence once unemployed have received a vacancy referral (VR).

In this study, we analyze the impact of vacancy referrals and sanctions on job search outcomes jointly. Moreover, we extend the evaluation of these measures by taking a potential avoidance strategy of the unemployed workers into account: the probability of reporting sick after activation. This is important for mainly two reasons. First, it gives us a more complete picture of the impact of job search assistance and monitoring on the behavior of unemployed workers. Second, evidence on the extent of the avoidance strategy conveys important insights into the value of vacancy referrals for the optimal job search behavior of unemployed job-seekers. Understanding these mechanisms will help to optimally target job search assistance and monitoring programs.

Our analysis is based on administrative data from West Germany for the period from 2000 to 2002. The data contain detailed information on unemployment duration, benefit receipt, sanctions, employment spells and daily wages. Moreover, we observe periods of sickness absence during unemployment. Another important feature of our data is that we observe whether or not the unemployed job seeker receives a VR in a given calender month. The estimation is based on an inflow sample of male workers into unemployment with repeated spells for part of the individuals. We estimate discrete-time duration models for the duration of unemployment and the duration until sanction, allowing for correlation between these two durations based on unobserved characteristics. Moreover, we estimate the probability of reporting sick and the probability of receiving a VR by the caseworker, both depending on the elapsed unemployment duration. To estimate causal effects on post-unemployment outcomes we additionally have to deal with dynamic selection into observed job matches based on unobserved heterogeneity. Hence, we jointly estimate six equations: the probability of receiving a VR, the probability of reporting sick, the duration until the imposition of a sanction, the duration until exit for a job, a wage equation for initial wages and the employment stability. The unobserved heterogeneity is modeled flexibly by a joint discrete distribution.

Our results show that receiving a vacancy referral by a caseworker increases the 
probability of leaving unemployment for a job. Jobs taken up shortly after receiving a VR have a significantly lower wage and are less stable than jobs found without previously receiving a VR. This suggests that on average job search via the public employment service (PES) leads to worse job quality than jobs found via private search. In addition to the direct effects of receiving a VR on job quality, there exist indirect effects via a reduction of the expected unemployment duration; wages and employment stability are decreasing with respect to elapsed unemployment duration. We perform simulations to take this into account. The simulation results show that individuals receiving VRs during their unemployment spell experience lower wages but have as stable jobs as job seekers who never receive any VR; this implies that in the case of employment stability the indirect effect via a shorter unemployment spell cancels out the direct effect. In line with evidence for other countries, sanctions lead to an increased job finding probability of unemployed workers and these jobs go along with significantly reduced wages. Furthermore, sanctions lead to less stable subsequent employment spells. These effects can be observed mainly within the first three months after the imposition of a sanction. Once the unemployed job seekers receive the full benefit amount again (after three months), the previously imposed sanction has no impact on the job finding probability any more.

Next to the increased exit rate to work, receiving a vacancy referral leads to an increase in the probability of reporting sick. This indicates that for some unemployed job seekers it is optimal to avoid applying for the assigned vacancy and to wait for better job offers. We find strong evidence for a variation of this avoidance behavior over time spent in unemployment. While we find a relatively strong impact of receiving a VR on the probability of reporting sick at the beginning of an unemployment spell, this effect is becoming smaller the longer individuals are unemployed. This suggests that the value of receiving a VR is increasing over time spent in unemployment. Based on the estimated coefficients we perform simulations to evaluate the importance of the impact of receiving a vacancy referral on the probability of reporting sick. Simulation results suggest that around $8.5 \%$ of the reported sickness spells are driven by the arrival of a vacancy referral. This indicates that the moral hazard due to the possibility to report sick plays an important role in the unemployment insurance system in Germany.

The paper is organized as follows: Section 2 describes the institutional background. Section 3 describes the data. In Section 4 we discuss the econometric approach. The results of the empirical analysis are presented in Section 5 and Section 6 concludes. 


\section{Institutional Background}

For this study, we conducted a qualitative survey among eight persons who worked as caseworkers during our observation period. This survey is - next to the wording of the law - an important source of information about the practical implementation of the rules for job search assistance and sanctions. The following description of the institutional settings refers to our observation period from January 2000 to December 2002.

\subsection{Unemployment Benefits}

In our observation period, unemployment insurance (UI) benefits are paid to individuals who are registered as unemployed and have been working and paying social security contributions for at least twelve months within the last three years prior to unemployment. The entitlement duration depends on the duration of the prior employment period and the age of the recipient. The maximum entitlement duration is 32 months for individuals who are older than 56 years and who have been employed for at least 64 months in the seven years previous to unemployment. Up to 2005, UI benefit recipients could receive means-tested unemployment assistance (UA) after their claim to UI benefits has expired. The monthly UI benefits amount to $67 \%$ of the previous monthly net wage for unemployed persons with child(ren) and to $60 \%$ for those without a dependent child. The replacement ratio for UA is $57 \%$ and $53 \%$, respectively. UA benefits are means-tested and (potentially) unlimited in time. For a detailed description of the unemployment insurance system in Germany and its changes over time see, e.g., Konle-Seidl, Eichhorst, and Grienberger-Zingerle (2010).

\section{$2.2 \quad$ Vacancy Referrals}

Vacancy referrals play an important role in job search assistance of unemployed workers in Germany. A VR is a placement referral in the form of a job description and typically contains the occupation, the working hours and the date of the potential job start. The jobs that are related to VRs cover a large variety of jobs ranging from job creation schemes to regular jobs. After receiving a VR, the unemployed has to apply for the job as soon as possible. However, a VR does not necessarily imply that a potential employer is already informed about the candidate or even that the employer intends to hire him. The application period depends on the sector and the occupation. According to the interviewed caseworkers, this period is on average longer for higher skilled jobs, but it is rarely longer than two weeks. For 
an unemployed individual, the VR is binding - in the sense that it could cause a sanction - if the job is suitable. In our observation period, suitability refers to the total daily commuting time and the wage level. The commuting time is not allowed to exceed two and a half hours. Within the first three months of UI benefit receipt, a job is suitable if the wage is not below $80 \%$ of the previous wage; between months four and six, this threshold drops to $70 \%$, and from the seventh month onwards, only those jobs are not suitable that offer a wage below the respective benefit level (Pollmann-Schult, 2005).

\subsection{Benefit Sanctions}

In our observation period, an unemployment benefit recipient is sanctioned by either a short-term or a long-term sanction when he did not comply with certain job search requirements. In the case of a sanction, UI or UA benefits are cut completely for a certain period. To prevent having no income, sanctioned individuals could apply for means-tested social assistance benefits, which is not related to previous wages. To pass the means-test for social assistance benefits, the unemployed individual has to prove that neither own savings nor the immediate family can cover the living costs.

There exist five reasons for sanctions: (1) When a person voluntarily quits his job, he does not receive any benefits for the first twelve weeks of unemployment. In the case of hardship, the sanction could be limited to six weeks and if the job would have ended within four weeks anyway, the person would have been sanctioned by three weeks only. (2) When a person refuses to search for a job or to work, by choosing not to apply for a suitable job that has been proposed to him as a vacancy referral (VR) or by rejecting a suitable job that has been offered to him, an unemployed is sanctioned by twelve weeks. If the corresponding job is temporary, the sanction period reduces to three weeks. Sanctions can also be imposed if the unemployed intentionally prevents the firm from making him a job offer, e.g., by misbehaving in the interview. For the caseworker it is difficult to prove such intention, and it depends mainly on the information flow between him and the firm whether he is informed about such misbehavior or not. However, the interviews with the caseworkers indicate that - although difficult - some unemployed individuals are sanctioned due to misbehavior during the job interviews. (3) Refusing participation or (4) dropping out of an active labor market policy (ALMP) measure would cause a sanction of twelve weeks. If the scheduled length of the measure is less than six weeks, the unemployed worker is sanctioned for six weeks. Finally, (5) when an unemployed person fails to report to the regional employment agency or to a medical or 
psychological appointment, he does not receive any benefit payments for two weeks (short-term sanction).

In this study we focus on long-term sanctions which are imposed during unemployment. We exclude sanctions which are imposed at the beginning of an unemployment spell due to reason (1) because - given our data - we cannot model selection into voluntary job quits. To avoid problems with reverse causality, we do not analyze the effects of short-term sanctions (reason 5). Having found a new job might be a reason for unemployed workers to fail to report to the regional employment agency or to miss a meeting with their caseworker, and hence might lead to a short-term sanction. Reverse causality should not be problematic regarding longterm sanctions: Before imposing a long-term sanction, the caseworker has to give the possibility of a hearing and once the unemployed justifies his infringement by having found a job, the sanction will not be imposed.

Sanctions are not imposed automatically, but at the discretion of the regional employment agency and the caseworkers (e.g. Müller and Oschmiansky, 2006). When imposing a sanction there are several moments when discretion can become relevant. Typically, the unemployed receives a letter from the caseworker containing a vacancy referral, or an invitation to a training program or to a personal meeting at the employment office. The letter also contains a legal note on the imposition of a sanction in the case of not applying, or not taking part in the training program, or missing the appointment. Once the caseworker discovers that the unemployed has not applied for the VR or not participated in the training, he has to give him the opportunity to justify his failure in a hearing. If the caseworker regards the justification as insufficient, i.e. if he discovers a legal infringement, he reports this to the benefits management department.

Whether an infringement is discovered depends on several circumstances, e.g., on the information flow between the caseworker and the human resources department of the firm offering the vacancy, or on the caseload, i.e. the number of unemployed assigned to one caseworker. The interviewed caseworkers emphasized the very high caseloads between 2000 and 2002, ranging from 400 to 1000 unemployed per caseworker. Having been informed about an infringement, the benefits management department checks the evidence against the unemployed and - in case of no objection - it stops the benefit payments and sends out a letter to the unemployed informing him about the imposition of a sanction but also about the possibility of filing an objection against the sanction within one month. In this paper we focus on imposed sanctions which have not been withdrawn. Once a sanction has been enforced, the unemployed has to follow the same job search requirements as before 
to avoid another sanction which could be added to the current one. When the cumulated duration of sanctions adds up to 24 weeks, a benefit recipient loses the claim to all benefits. According to the interviewed caseworkers, while some of them mentioned having monitored sanctioned unemployed more carefully, generally, they did not increase monitoring and counseling, and specifically, they did not send out more vacancy referrals to test their availability for work than before a sanction.

\subsection{Sick Leave among Unemployment Benefit Recipients}

In the case of temporary disability due to sickness, benefit recipients are required to call in sick and to submit a doctor's note confirming their illness. During the first six weeks of sickness, UI or UA benefits continue to be paid by the PES. Within this period, the potential UI benefit duration continues to decline. If, during an ongoing spell of benefit receipt, the cumulated period of sickness (with the same diagnosis) exceeds six weeks, the unemployed person has to apply to the health insurance agency for sickness benefits. ${ }^{1}$ Thus, since the system does not provide any advantages connected to sickness - such as higher benefits or as an extension of benefit duration - it provides no financial incentive per se for benefit recipients to take sick leave in the case of short-term illness.

Incentives to take sick leave do arise, however, from job search requirements and job search assistance: to be eligible for benefits, recipients have to comply with job search requirements. Otherwise, they risk having their benefits cut as described above. During sickness, minimum requirements on search behavior do not apply and therefore unemployed individuals cannot be sanctioned. First, this implies an incentive to take sick leave in the case of real sickness. Second, there is an incentive to call in sick after having received a VR, i.e., individuals who want to avoid applying to the assigned job vacancy might report sick.

An important feature of the German system is that benefit recipients are free to choose the doctor themselves. This implies that they can search for a doctor who is willing to hand out a sick note. There does not exist a direct way for the caseworker to check the reliability of a sick note. Instead, the caseworker can send the unemployed to the medical service of the PES (Ärztlicher Dienst) to check general work related health restrictions. However, the medical service of the PES should not be able to "falsify" another doctor's sick note, since usually, the respective period

\footnotetext{
${ }^{1}$ Eligibility for sickness benefits requires a specific doctor's certificate (cf. e.g. Ziebarth and Karlsson, 2010). The health insurance can involve a certified doctor of the medical service of the health insurance (Medizinischer Dienst der Krankenversicherung) to verify that certificate. In this paper, we focus on short-term sickness and treat observations as censored when they enter sickness benefits.
} 
of sickness absence can only be investigated retrospectively by them.

\section{Data}

We use administrative records of the German Public Employment Service (Bundesagentur für Arbeit). The data are provided by the Institute for Employment Research (IAB). More specifically, we use the integrated employment history (Integrierte Erwerbsbiographien, IEB) and the applicants pool database (Bewerberangebot, BewA). The IEB consists of different sources, e.g., employment history, benefit recipient history, training participant history and job search history and therefore contains detailed information on employment subject to social security contributions, unemployment and participation in active labour market policy including wages and transfer payments. The data additionally include a broad range of socioeconomic characteristics including education, family status and health restrictions. The data do not contain information about the working hours and periods in selfemployment, working as a civil servant, or spent in inactivity. A detailed description of the IEB is for example given by Dundler (2006).

\subsection{Sample}

We draw a random sample of individuals entering unemployment insurance benefit receipt between January 12000 and December 31 2000. Prior to the unemployment entry the individuals have to be employed subject to social security contributions for a minimum duration of 12 months to ensure that we have a "real" inflow sample into unemployment and to reduce the amount of seasonal unemployment spells in our data. During our observation period, East and West Germany still differ substantially in terms of economic and labour market indicators. The share of unemployed individuals entering public employment programs and receiving a corresponding VR is considerably higher in East than West Germany. Since we are interested in transitions into unsubsidized jobs, we focus on West Germany. Moreover, we focus on male job seekers. For the primary carer of children below age three, job search requirements are different. Since this concerns more often women than men, (endogenous) fertility - if not accounted for - might bias the estimated effects of VRs and sanctions on job search outcomes of female job seekers. Furthermore, the high share of part-timers among women renders an evaluation of wages in the first job after leaving unemployment difficult as we do not observe working hours. Therefore, focusing on men in West Germany keeps the estimated model manageable and leads 
to a relatively homogenous estimation sample.

Additionally, we drop individuals with a university degree from the estimation, because there are only very few individuals with university degree who are sanctioned in our data. We focus on individuals who are older than age 24 years and younger than 58 years when entering unemployment benefit receipt. The lower age restriction is motivated by the educational system, and the upper by the retirement schemes. We right-censor spells once an individual becomes 58 years old. We restrict our observation period from January 12000 to December 31 2002, since in 2003 several labor market reform have been introduced. We treat durations as right-censored at December 31 2002. Thus, we have an observation window of three years. Our final sample consists of 106,978 individuals.

\subsection{Treatment and outcome variables}

We are interested in the effect of two treatments - receiving a VR and being sanctioned - on unemployment duration and job quality. Additionally, we model the impact of receiving a VR on the probability of reporting sick.

Individuals can be sanctioned effectively only if they receive transfer payments. Therefore, unemployment duration is defined as the duration of benefit receipt. We do not distinguish between UI and UA spells, because the institutional rules with respect to VR and sanctions are the same for both types of benefit payments. If individuals leave benefit receipt without finding an unsubsidized job, exit to subsidized employment, or to active labor market policy schemes where they receive training measure benefits (Unterhaltsgeld, UHG), the unemployment spells are treated as right censored. ${ }^{2}$ Transitions to UHG are right-censored because we do not observe sanctions in our data during the receipt of this type of transfer payments.

To define the arrival time of the VRs we use information in the applicants pool database (BewA). Most of the VRs were reported at the end of a month to the statistical department of the PES. Hence, instead of observing the exact VR arrival day, we know whether or not a person has received a VR in a given calender month. Unfortunately, there is no further information about the VRs available, such as the offered wage or the occupation.

Since the application periods are usually not longer than two weeks, by reporting sick for two weeks or longer, individuals can avoid an application to the assigned vacancy. Therefore, we consider sickness absence spells during unemployment that are longer than 13 days. Since the VRs are observed in discrete time, we discretize

\footnotetext{
${ }^{2}$ For the definition of an exit from unemployment to employment we allow for gaps of up to 31 days between the end of benefit receipt and the start of an employment spell.
} 
information in the data on a monthly basis. We define an individual as (un)employed and, respectively, sick in a given calendar month, if he spends at least one day of that calendar month in (un)employment and, respectively, sickness absence.

The data contain information on sanctions that are imposed during UI or UA benefit receipt. These sanctions are short-term sanctions due to missing an appointment as described above and long-term sanctions imposed due to refusing a VR or refusing a training measure. As discussed above, we focus on long-term sanctions and ignore short-term sanctions. Furthermore, in those cases where more than one long-term sanction during one unemployment spell was imposed, we analyze the first sanction only. In our sample, only around $3 \%$ of the sanctioned individuals are sanctioned more than once during one unemployment spell. Unfortunately, we cannot distinguish the two reasons for long-term sanctions. However, according to statistics of the PES, sanctions due to refusing a VR were imposed about four times more often than sanctions due to refusing a training measure (Bundesagentur für Arbeit, 2004).

The employment duration is defined from the start of the first regular job until reentry into unemployment. We define an individual as being regularly employed if he holds a job where he is paying social security contributions and does not receive any benefits from PES at the same time. Minor employment - so called mini jobs - is not considered as regular employment in our analysis. We use the initial daily gross wage as an indicator for the quality of the first post-unemployment job. Since the actual working time is not stored in the data, we do not have information about hourly wages. Moreover, the wage information is right censored at the social security contribution ceiling. This aspect should have no impact on our analysis, since the vast majority of the observed post-unemployment wages is below this threshold. ${ }^{3}$

\subsection{Descriptive Statistics}

Table 1 provides descriptive statistics about the number of spells and events observed in our full sample. We have multiple spell data and we consider all unemployment spells and subsequent employment spells within our observation period. $57.5 \%$ of the individuals are observed in unemployment only once and $2.5 \%$ more than three times. Overall we observe 169,876 unemployment spells, of which $54.7 \%$ have a transition to regular employment. Around $70 \%$ of our sample receive at least one $\mathrm{VR}$, and among them the majority receives more than one VR during their period of

\footnotetext{
${ }^{3}$ In 2002, e.g., the ceiling level was 4.500 Euro (West Germany), and respectively 3.750 Euro (East Germany). Only about $1.2 \%$ of our sample took up a job that was paid more than 4.000 Euro.
} 
unemployment. Only a small share of unemployed individuals are sanctioned during their receipt of transfer payments (around 2\%), and only 31 individuals have more than one unemployment spell with a long-term sanction during our observation period. Around 10\% report sick during unemployment. We observe around 93,000 employment spells in our data, and $40 \%$ of these employment spells end with an entry into unemployment. The average initial daily gross wage of these employment spells is $65 €$.

[Table 1 about here]

Figure 1 depicts the unconditional monthly transition rates to sanctions and regular employment and the probabilities of receiving a VR and reporting sick during unemployment. The probability of finding a job is first increasing and after three month decreasing. The unconditional probability of receiving a VR is relatively high at the beginning of an unemployment spell (around 24\%), and decreasing to around $12 \%$ after 24 months, while the probability of reporting sick is increasing over time spent in unemployment from around $2 \%$ in the first month to about $5 \%$ after 24 months. The probability of being sanctioned is rather low (around $0.2 \%$ ) and does not change during the unemployment spell.

[Figure 1 about here]

In Figure 2 the share of individuals receiving a VR and the share of individuals leaving unemployment for a job are plotted for the sample of individuals who have been sanctioned during their unemployment spell. Being sanctioned is highly associated with the arrival of a VR: in the month before the sanction, around $62 \%$ of the individuals receive a VR, which is a high share compared to an (average) VR arrival rate of around $20 \%$ among the non-sanctioned in the first ten months of benefit receipt. After the imposition of a sanction, the probability of receiving a VR drops to a similar probability as before the imposition of a sanction. Regarding the unconditional association of the imposition of a sanction and an exit to employment, Figure 2 suggests that the hazard to employment is relatively high in the three months after the imposition of the sanction ranging between 0.08 and 0.13.

[Figure 2 about here]

Figure 3 indicates a positive association between the timing of receiving a VR and the probability of reporting sick. This graph is based on individuals who report sick at least once during their unemployment spell. In the month of the sickness absence, 
we observe an increase in the probability of receiving a VR. The probability of leaving unemployment for a job is rather low compared to the job finding probability in the whole sample (see Figure 1).

[Figure 3 about here]

Table 2 lists descriptive statistics for selected covariates by different (overlapping) subsamples: by sanction status, by sickness absence and by VR receipt. A comparison of the observed characteristics shows for example that sanctioned individuals are on average younger than never sanctioned unemployed workers, are less often German, and are more often singles and have less often children. Moreover, they have on average a lower skill level: the share of sanctioned individuals holding a medium school degree (Mittlere Reife) and the highest school degree (Fachhochschulreife or Abitur) is around $16.1 \%$ and $6.0 \%$ compared to $18.4 \%$ and $10.3 \%$, respectively, among the non-sanctioned individuals. In line with this, the share of sanctioned individuals holding a vocational training degree is lower (49.2\% vs. $59.6 \%)$. Sanctioned individuals live in regions where on average the local unemployment rate is lower compared to the regions where those without sanction live ( $7.8 \%$ vs. $8.5 \%)$, while the vacancy rate is higher $(16.6 \%$ vs. $14.9 \%)$. The local unemployment rate and the vacancy rate are measured on a monthly basis and on the level of regional employment agency. ${ }^{4}$ We also observe differences between individuals who are sick at least once during our observation period and individuals who are never sick as well as between unemployed workers who receive at least once a VR and unemployed individuals who never receive a VR. For example, individuals who report sick at least once during unemployment are on average lower skilled (5.5\% vs. $10.8 \%$ hold the highest schooling degree) and individuals who never receive a VR are on average slightly older (at the start of their first unemployment spell) than unemployed who receive job search assistance in form of a vacancy referral (39.5 vs. 37.8 years).

[Table 2 about here]

\section{Empirical Model}

We want to measure the causal impact of receiving a VR and of the imposition of a sanction on job search outcomes. The selection into the two treatments can occur

\footnotetext{
${ }^{4}$ In Germany, there are about 180 regional employment agencies, where about 140 are located in West Germany. The local vacancy rate corresponds to the number of open vacancies, registered at the regional employment agency, divided by the number of unemployed workers in that region.
} 
at different points in time during an unemployment spell, and the probability of entering a treatment and leaving unemployment for a job might depend on elapsed unemployment duration and on individual characteristics. This dynamic selection over time and into the treatments - depending on observed and potentially on unobserved individual characteristics - has to be taken into account.

Our empirical approach is based on the timing of events approach of Abbring and van den Berg (2003). We estimate duration models for the duration of unemployment and the duration until the imposition of a sanction, and we additionally estimate the probability of receiving a VR and of reporting sick during unemployment. Since we observe the labor market states on a monthly basis, we estimate discrete time duration models. Heckman and Navarro (2007) provide a discussion of a discrete time analogue of the continuous time duration model presented by Abbring and van den Berg (2003). For the evaluation of the treatment effects on job quality, we additionally estimate the probability of re-entering unemployment and a wage equation for the initial wage, see e.g. Ham and LaLonde (1996), van den Berg and Vikstroem (2012) and Caliendo, Tatsiramos, and Uhlendorff (2012) for similar approaches.

As depicted in Table 1, our dataset contains multiple observations for some individuals, which facilitates the identification and estimation of the joint distribution of the unobserved heterogeneity variables (see e.g. Honore, 1993). Moreover, our dataset includes time-varying variables such as the local unemployment rate. Eberwein, Ham, and LaLonde (1997) and Gaure, Roed, and Zhang (2007) emphasize that time-varying covariates provide exclusion restrictions because past values affect current transition probabilities only through the selection process, i.e. timevarying covariates provide a more robust source of identification than time-invariant covariates. These features of the dataset imply that identification does not solely rely on the functional form of the model.

We observe an inflow sample into unemployment. We assume that the treatment probabilities, the probability of reporting sick and the probabilities of leaving unemployment for a job and of re-entering unemployment can be expressed by logistic specifications. The results do not change if we alternatively choose a complementary log-log specification for the monthly probabilities.

\subsection{Selection into treatment}

We estimate the selection into two types of treatment during unemployment: the probability of receiving a vacancy referral $\theta_{v}(t)$ and the probability of being sanc- 
tioned $\theta_{s}(t)$. Some of the unemployed individuals in our sample receive more than one VR in a given month $t$. However, we do not model this "treatment intensity", since receiving more than one $\mathrm{VR}$ in a month might be the consequence of unsuccessful applications to previous job offers in the same month or reflect several job offers at the same time, which we cannot distinguish given the discrete observation of the VR arrival. Unemployed individuals can receive VRs in several months during their unemployment spell.

We assume that all individual differences in the arrival probability of a VR in period $t$ can be characterized by observed characteristics $x$, the elapsed unemployment duration $t_{u}$, and the unobserved characteristics $V_{v}$ :

$$
\theta_{v}(t)=\frac{\exp \left(\beta_{0 v}+\sum_{d=2}^{k} \beta_{1 d v} I_{u d}\left(t_{u}\right)+x_{t}^{\prime} \beta_{2 v}+V_{v}\right)}{1+\exp \left(\beta_{0 v}+\sum_{d=2}^{k} \beta_{1 d v} I_{u d}\left(t_{u}\right)+x_{t}^{\prime} \beta_{2 v}+V_{v}\right)}
$$

The effect of duration dependence is modeled in a flexible way by using time dummy variables denoted as $I_{u d}\left(t_{u}\right)$, which are equal to one when duration in unemployment $t_{u}$ is within the duration interval denoted by the subscript $d=(2, \ldots, k)$.

Similarly, we assume that all individual differences in the probability of being sanctioned in period $t$ can be characterized by observable characteristics $x$ and unobserved characteristics $V_{s}$. In addition to that, the sanction probability depends on whether or not the unemployed received a $V R$ in $t$ or in $t-1$.

$$
\theta_{s}(t)=\frac{\exp \left(\beta_{0 s}+\sum_{d=2}^{k} \beta_{1 d s} I_{u d}\left(t_{u}\right)+x_{t}^{\prime} \beta_{2 s}+V R_{t} \alpha_{s}+V_{s}\right)}{1+\exp \left(\beta_{0 s}+\sum_{d=2}^{k} \beta_{1 d s} I_{u d}\left(t_{u}\right)+x_{t}^{\prime} \beta_{2 s}+V R_{t} \alpha_{s}+V_{s}\right)}
$$

\subsection{Probability of sickness absence}

We observe whether or not individuals report to be sick while being unemployed in month $t$. We assume that all individual differences in the probability of sickness absence in period $t$ can be characterized by observed characteristics $x$, the elapsed unemployment duration $t_{u}$, whether or not the unemployed received a $V R$ in $t$ or in $t-1$, and the unobserved characteristics $V_{s a}$. The probability of reporting sick $\theta_{s a}(t)$ is given by:

$$
\theta_{s a}(t)=\frac{\exp \left(\beta_{0 s a}+\sum_{d=2}^{k} \beta_{1 d s a} I_{u d}\left(t_{u}\right)+x_{t}^{\prime} \beta_{2 s a}+V R_{t} \alpha_{s a}+V_{s a}\right)}{1+\exp \left(\beta_{0 s a}+\sum_{d=2}^{k} \beta_{1 d s a} I_{u d}\left(t_{u}\right)+x_{t}^{\prime} \beta_{2 s a}+V R_{t} \alpha_{s a}+V_{s a}\right)}
$$


Unemployed individuals can report sickness in several periods during their unemployment spell.

\subsection{Unemployment duration}

We assume that the probability of leaving unemployment for a job in period $t$ depends on $x$, whether or not the unemployed received a $V R$ in $t$ or in $t-1$, whether or not the unemployed reported sick in $t$, unobserved characteristics $V_{u}$, and a sanction effect if a sanction has been imposed before or in the period $t$.

$I(\cdot)$ takes on the value one if $t>=t_{s}$ and $\delta_{u}$ is the effect of a sanction on the probability of finding a job. The variable $V R_{t}$ is one if the unemployed received a vacancy referral in the current or in the previous period, otherwise zero, and $\kappa_{u}$ is the effect of receiving a VR on the probability of finding a job. $S A_{t}$ takes on the value one if the unemployed is reporting sick in period $t$, otherwise zero.

$\theta_{u}(t)=\frac{\exp \left(\beta_{0 u}+\sum_{d=2}^{k} \beta_{1 d u} I_{u d}\left(t_{u}\right)+x_{t}^{\prime} \beta_{2 u}+V R_{t} \alpha_{u}+I\left(t \geq t_{s}\right) \delta_{u}+S A_{t} \kappa_{u}+V_{u}\right)}{1+\exp \left(\beta_{0 u}+\sum_{d=2}^{k} \beta_{1 d u} I_{u d}\left(t_{u}\right)+x_{t}^{\prime} \beta_{2 u}+V R_{t} \alpha_{u}+I\left(t \geq t_{s}\right) \delta_{u}+S A_{t} \kappa_{u}+V_{u}\right)}$

We assume that a sanction and a VR do not affect the probability of leaving unemployment for a job before the moment of the sanction and the moment of the receipt of a VR, respectively. This assumption is called the no-anticipation assumption. In the case of sanctions this assumption is very likely to hold, since the exact moment when a caseworker imposes a sanction cannot be anticipated by the unemployed, see Section 2. The same holds for the VR. The unemployed might know the probability of receiving a VR, but it is very plausible that he does not know the exact timing of the arrival of a VR.

\subsection{Post-unemployment outcomes}

We measure the job match quality by the initial wage and by the monthly probability of reentering unemployment. We allow both outcomes to depend on unobserved characteristics which might be correlated with the unobserved factors $V_{u}, V_{s}, V_{v}$ and $V_{s a}$. In order to identify the causal impact of sanctions and of having received a VR in the last two months of unemployment on realized wages, we assume that the unobserved heterogeneity and the causal effect have an additive impact on the mean log wage. We specify following wage equation for the wage at the beginning of the 
new employment spell:

$$
\ln w=\beta_{0 w}+\sum_{d=2}^{k} \beta_{1 d w} I_{u d}\left(t_{u}\right)+x_{t}^{\prime} \beta_{2 w}+I\left(t_{s} \geq t_{u}\right) \delta_{w}+t_{u} \eta_{w}+V R_{t} \alpha_{w}+V_{w}+\varepsilon_{w}
$$

The sanction effect is given by $\delta_{w}$, the effect of receiving a vacancy referral in the last two months of unemployment is given by $\alpha_{w}, V_{w}$ is the unobserved heterogeneity, and $\varepsilon_{w}$ is assumed to be normal distributed with mean zero and unknown variance $\sigma_{w}$. In addition, we allow the log wage to vary with respect to the previous unemployment duration $t_{u}$. We control for duration of the previous unemployment spell $t_{u}$ by using time dummy variables.

Similarly to the duration of unemployment we specify a duration of employment, described by the probability to leave employment and to reenter unemployment in period $t$. $\delta_{e}$ captures the causal effect of an imposed sanction in the previous unemployment spell and $\alpha_{e}$ the effect of having received a vacancy referral in the last two months of unemployment. The probability of leaving employment in period $t$ is given by:

$$
\theta_{e}(t)=\frac{\exp \left(\beta_{0 e}+\sum_{d=2}^{k} \beta_{1 d e} I_{e d}\left(t_{e}\right)+\sum_{d=2}^{k} \beta_{2 d e} I_{u d}\left(t_{u}\right)+x_{t}^{\prime} \beta_{e}+I\left(t_{s} \leq t_{u}\right) \delta_{e}+V R_{t} \alpha_{e}+V_{e}\right)}{1+\exp \left(\beta_{0 e}+\sum_{d=2}^{k} \beta_{1 d e} I_{e d}\left(t_{e}\right)+\sum_{d=2}^{k} \beta_{2 d e} I_{u d}\left(t_{u}\right)+x_{t}^{\prime} \beta_{e}+I\left(t_{s} \leq t_{u}\right) \delta_{e}+V R_{t} \alpha_{e}+V_{e}\right)}
$$

Similarly to the wage equation we allow $\theta_{e}$ to vary with respect to the previous unemployment duration $t_{u}$.

\subsection{Distribution of unobserved heterogeneity}

We assume that the unobserved heterogeneity terms are constant over time, i.e., across repeated spells of unemployed individuals, and that they are not correlated with observed characteristics $x$. We specify the distribution of unobserved heterogeneity $G$ to have a discrete support with $M$ support points. However, the unobserved heterogeneity terms of the different processes might be correlated with each other. In order to force the corresponding probabilities to be between zero and one and to sum to one we use a multinomial logit parameterization of the class probabilities:

$$
\pi_{m}=\frac{\exp \left(\omega_{m}\right)}{\sum_{m=1}^{M} \exp \left(\omega_{m}\right)}, \quad m=1, \ldots, M, \quad \omega_{1}=0
$$


Each of the six components of the unobserved heterogeneity $V$ takes on a specific value at support point $m$. This implies that for a model with $M=2 G$ would be described by 7 parameters, for $M=3$ we estimate 14 parameters, etc. This approach allows for a flexible covariance matrix for the unobserved components. For a similar model for unobserved heterogeneity in the context of timing of events models see Crepon, Ferracci, Jolivet, and van den Berg (2010) and in the context of random coefficient models in the statistical literature see e.g. Aitkin (1999). Gaure, Roed, and Zhang (2007) provide Monte Carlo evidence that modeling selection based on unobservables by a flexible discrete distribution works well in the context of timing of events models. In the estimation we increase the number of support points until the model fit cannot be improved by a further support point anymore, evaluated on the basis of the Akaike Criterion, or until we cannot increase the number of support points any further because the corresponding estimator does not converge. ${ }^{5}$

The individual likelihood contribution for a specific support point $m$ is described by $l_{i t}\left(x_{i t}, V_{m}\right)$. The log likelihood for the whole sample is given by:

$$
L L=\sum_{i=1}^{N} \ln \left(\sum_{m=1}^{M} \pi_{m} \prod_{t=1}^{T}\left[l_{i t} \mid x_{i t}, V_{m}\right]\right)
$$

\section{Results}

First, we present results of a baseline model which allows for homogeneous treatment effects. Second, we introduce time-varying treatment effects by interacting the treatment indicator for receiving a VR with elapsed unemployment duration and allow the impact of a sanction to be different during the first three months after the imposition of a sanction and thereafter. Finally, we perform simulations of the outcomes based on the estimated coefficients. These simulations give us insights about the extent to which receiving vacancy referrals during unemployment increases the share of unemployed job seekers who are reporting sick. Moreover, VRs might have - next to the direct effects which are reflected by the coefficients - indirect effects on the job quality via a reduction of the time spent in unemployment. The simulated outcomes give us the overall impact of receiving VRs on daily wages and employment duration.

\footnotetext{
${ }^{5}$ The estimation we have employed was ML using the BHHH algorithm. For this we use analytic first derivatives of the likelihood function with respect to the estimated parameters.
} 


\subsection{Baseline Specification}

In Table 3 we report the treatment effects for different outcomes. We control for observed characteristics as reported in Table 1 and allow for flexible duration dependencies for the duration in unemployment and employment and for the corresponding probabilities of being treated and of reporting sick during unemployment. Moreover, we control for the sector of the previous employment spell, the quarter in which the unemployment spell starts and include time-varying indicators for the current quarter to capture seasonal effects. Our final specification includes 6 support points $(M=6)$, which implies that we estimate 35 additional parameters for the distribution of unobserved characteristics compared to a model without unobserved heterogeneity. A further increase of the number of support points is not possible, i.e., we cannot achieve convergence of a model with more than 6 support points. The inclusion of unobserved heterogeneity significantly improves the model fit. Compared with model without unobserved heterogeneity, the log likelihood increases from $-1203,553.02$ to $-1135,843.16$.

[Table 3 about here]

Receiving a vacancy referral has a strong positive effect on the probability of leaving unemployment for a job (Table 3). The probability of an exit to work increases by around $76 \%$ in the current period and in the period after receiving a VR. ${ }^{6}$ However, jobs which are found after receiving a VR have on average slightly lower wages $(-2.6 \%)$ and the probability of reentering unemployment is higher: the corresponding coefficient indicates that the probability of reentering unemployment increases by around $7 \%$. This suggests that job referrals from the case worker lead to jobs of worse quality compared to jobs found through alternative search channels. In line with these results, we find a strong positive effect of receiving a VR on the probability of reporting sick. This probability increases by around $60 \%$ in the months $t$ and $t+1$ if the unemployed receives a $\mathrm{VR}$ in $t$. This suggests that for some individuals it is optimal to avoid applying at the assigned vacancy and to wait for better job offers.

Given that refusing to apply to a vacancy or not going to a job interview are the main reasons for the imposition of a sanction, we find a strong effect of receiving a VR on the probability of being sanctioned: unemployed job seekers have an

\footnotetext{
${ }^{6}$ The corresponding coefficient of the dummy variable in the logit model is 0.56 . Taking the exponential of this coefficient gives us the ratio of the exit rates between unemployed workers receiving and not receiving a VR. This ratio implies that the exit rate for treated individuals is around $76 \%$ higher than the exit rate of non-treated individuals.
} 
around six times higher probability of being sanctioned after receiving a VR. These sanctions lead to a significant increase in the job finding probability by around $28 \%$. However, sanctions go along with a lower job match quality. Our results indicate that sanctions push job seekers into employment spells which have lower wages and which are less stable. The period-specific probability of reentering unemployment is around $27 \%$ higher and the initial wages of workers who have been sanctioned during unemployment are around $11 \%$ lower than the wages of workers who have not been sanctioned.

The complete set of coefficients of the models without and with unobserved heterogeneity are reported in the Appendix in Table A.1 and Table A.2, respectively. For example, the results suggest that the local unemployment rate is negatively correlated with the probability of receiving a VR, of leaving unemployment for a job, and of being sanctioned, while the probability of reporting sick is not correlated with the local unemployment rate. A higher unemployment rate goes along with lower initial wages and more stable employment spells. Age is negatively correlated with the job finding probability, the probability of being sanctioned and the probability of receiving a VR, while the probability of reporting sick is increasing with age. Older workers have higher initial wages, but their employment spells after leaving unemployment are on average less stable. Sickness absence goes along with a significantly lower probability of finding a job. This is in line with our expectations, since sickness absence goes along with a reduced search effort and a reduced job offer arrival rate.

The correlation coefficients between the different components of the unobserved heterogeneity are reported in Table A.3 in the Appendix. The results indicate for example that individuals who have (conditional on observed characteristics) a higher probability of being sanctioned have on average lower wages and are longer unemployed. While we find evidence for a positive correlation between unobservables influencing the probability of receiving a VR and unobservables having an impact on the probability of finding a job, our results suggest a negative correlation between the probability of reporting sick and the probability of receiving a VR. Furthermore, the unobserved factors influencing the receipt of a vacancy referral are highly correlated with the probability of being sanctioned.

\section{$5.2 \quad$ Time Varying Treatment Effects}

In a next step, we introduce time-varying treatment effects for being sanctioned and for receiving a VR. Long sanctions usually imply a benefit cut of $100 \%$ for 
three months, and after three months sanctioned individuals receive the full amount of benefits again (see Section 2). Therefore, we allow the impact of a sanction to be different during the first three months after the imposition of a sanction and thereafter. Table 4 presents results for time-varying effects of the imposition of a sanction. ${ }^{7}$ We find strong evidence for time-varying sanction effects: the impact of being sanctioned on the probability of leaving unemployment for a job is significantly positive in the first three months after the imposition $(+40 \%)$. After three months, the point estimate is still positive, but not significantly different from zero anymore.

[Table 4 about here]

Additionally, we find time-varying effects of a sanction on the job match quality. Being sanctioned leads to less stable employment spells if sanctioned individuals leave for a job within the first three months after the imposition of the sanction $(+30 \%)$. This effect is smaller and not significant anymore after three months. The impact on the initial wages is especially high shortly after the imposition of a sanction. The wages are around $14 \%$ lower than the wages of not sanctioned individuals. We still find significantly lower wages for later exits to work, but the effect is much smaller if sanctioned individuals take up a job when they receive full benefit payments again $(-4.5 \%)$.

Moreover, we interact the treatment indicator for receiving a VR with elapsed unemployment duration. The coefficients in Table 5 indicate that the effect of receiving a VR on the probability of being sanctioned as well as the effect on the probability of leaving unemployment for a job are rather stable over time spent in unemployment. For both probabilities, the point estimates of the VR effect in months 1-3 are not significantly different from the point estimates in months 19-36. Receiving a VR leads to an increase of around $79 \%$ in the probability of finding a job shortly after entering unemployment as well as for individuals who are unemployed for more than 1.5 years, while receiving a VR leads to a more than seven times higher probability of being sanctioned.

[Table 5 about here]

We find strong evidence for time-varying effects of receiving a VR on the probability of reporting sick. While the receipt of a VR leads to an increase of around $93 \%$ at the beginning of an unemployment spell, this effect drops to around $17 \%$

\footnotetext{
${ }^{7}$ The coefficients for observed characteristics are reported in Table A.4. The correlations between the components of the unobserved heterogeneity look very similar to the corresponding correlations of the baseline model. They are not reported here, but are available on request.
} 
after more than 1.5 years of unemployment. The corresponding coefficients are significantly different from each other. This decline in the impact on reporting sick indicates that the avoidance of VRs becomes less attractive the longer job seekers are unemployed. This could be explained by a decreasing value of continuing job search over time spent in unemployment, which could be induced by a decrease in the job offer arrival rate or by the decreasing profile of the transfer payments (after exhaustion of UI benefits individuals receive UI assistance, see Section 2 for details). In both cases it is more attractive for the unemployed job seeker to go on searching for a (better) job offer at the beginning of an unemployment spell than after a long time spent in unemployment. This drop in the value of unemployment decreases the incentive to report sick after receiving a VR.

The job match quality is lower if unemployed job seekers find a job after receiving a VR, independent of the elapsed unemployment duration. However, at the beginning of an unemployment spell, this is mainly driven by differences in wages. We find significant lower wages in the first 9 months of unemployment $(-3.9 \%,-1.6 \%$ and $-1.4 \%$, respectively). After more than 9 months of elapsed unemployment duration, the difference in wages is not significant any more. While we find a rather small effect on employment stability for jobs found in months 1-3 of unemployment and no significant impact for months 4-6, jobs found after the first half year of unemployment duration are significantly less stable if individuals have received a VR shortly before the start of the employment spell. The increase of the monthly probability of reentering unemployment ranges from $23 \%$ to around $29 \%$.

\subsection{Simulations}

The coefficients reported in the previous section give us insight into the direction and the relative size of the effects of receiving a vacancy referral on the probability of reporting sick. In order to get an idea of the importance of these effects, we perform simulations of the outcomes. These simulations are based on the estimated coefficients and are performed for the average unemployed worker in our sample with respect to observed characteristics. For this average unemployed job seeker we calculate the weighted average with respect to the different support points of the unobserved heterogeneity. We compare two situations, (i) a situation in which we allow for an effect of receiving a vacancy referral on the probability of reporting sick, and (ii) a situation in which we set this effect to zero, i.e., we assume that workers do not react in their sickness absence on the arrival of a vacancy referral. The standard errors of average probabilities are computed using parametric bootstrap based on 
250 draws from the covariance matrix of the estimated parameters (Skrondal and Rabe-Hesketh, 2009).

[Figure 4 about here]

In Figure 4 the simulated probability of sickness absence is plotted with and without allowing for an effect of VR. The predicted sickness absence is increasing over time, which is in line with the observed sickness patterns (see Figure 1). While the difference in the shares of individuals reporting sick is significant in every month of unemployment, this difference is - as expected given the time-varying coefficients - relatively strong at the beginning of the unemployment spell, and is decreasing with elapsed unemployment duration. Overall, the share of months in which job seekers report sick increases by around $8.5 \%$ once we allow for an effect of receiving a VR. This relative increase is around $16 \%$ in the first 6 months of unemployment and decreases to around $3.5 \%$ for the months 19 onwards. The total share of months with sickness absence during unemployment increases from $3.1 \%$ to $3.4 \%$. This indicates that the moral hazard due to the possibility to report sick plays an important role in the unemployment insurance system in Germany.

For the evaluation of the overall impact of receiving a VR on the initial wages and the employment stability, we have to take the indirect effect via the reduction of the unemployment duration into account. The coefficients for the lagged unemployment duration in Table A.4 indicate that the initial wages are decreasing with respect to elapsed unemployment duration. Since the receipt of a VR significantly reduces the unemployment duration, this indirect effect should reduce the negative impact of receiving a VR on initial wages. The same holds for the expected employment stability: jobs found after the first three months are less stable than jobs found in the beginning of an unemployment spell. In order to investigate the overall effects, we simulate the unemployment duration, the initial wage and the employment duration for the average individual in our sample for (i) a situation in which the unemployed worker has the standard probability of receiving a VR in every month and compare this with (ii) a situation in which he does not receive any VR during his unemployment spell. In addition to that we simulate the outcomes for (iii) a situation in which the unemployed job seeker does not receive any VR during the first three months of unemployment, but has the standard treatment probability after month 3 .

[Table 6 about here]

Our simulations show that not receiving a VR increases the expected time spent in unemployment from 14.39 to 16.70 months, see Table 6. Despite this increase 
in the unemployment duration, the initial wages are higher in the scenario without any VR. This indicates that the direct (negative) effect on initial wages is dominating. The daily wages of jobs found during unemployment increase from 55.00 to 55.68 Euro. However, the expected duration of the employment spell in both scenarios around 28.5 months. ${ }^{8}$ For the employment stability, the indirect effect via the impact on the (elapsed) unemployment duration on the probability of reentering unemployment cancels out the direct impact. The differences in time spent in unemployment and in initial wages are significant at a $1 \%$ level. In a situation in which individuals do not get any VR during the first three months, the average realized wage is 56.93 Euro and the expected time spent in unemployment is around 15 months. The relatively strong difference in initial wages compared to the standard treatment with a potential receipt of a VR in every month during unemployment reflects that the negative direct effect of a VR on initial wages is especially important at the beginning of an unemployment spell (see Table 5). The employment spell for scenario (iii) lasts on average around 28.4 months, i.e. it is almost the same as in scenarios (i) and (ii). This suggests that not receiving a VR in the first three months slightly increases the expected time spent in unemployment, but goes along with an around $1.7 \%$ higher daily wage.

We additionally performed simulations for the impact of imposed sanctions. The results show that sanctioned individuals have significantly shorter unemployment spells, lower initial daily wages and shorter employment spells. For example, imposing a sanction in the third month of unemployment reduces the expected unemployment duration from 14.2 to 12.3 for the average unemployed job seeker in our sample. The expected daily wage drops from 53.2 to 47 Euro and the expected duration of the employment spell decreases from 28.2 to 26.7 months.

\subsection{Discussion of the results}

We find strong evidence for an increased probability of sickness absence after individuals receive a VR. We have argued that this finding can be interpreted as an avoidance strategy, i.e., some unemployed job seekers try to avoid an application to an assigned job vacancy and the risk of being sanctioned, respectively, by reporting sick. However, there exists an alternative explanation for our findings. It is possible that the effect of a VR on sickness absence partly reflects late reporting of real sickness: unemployed who are too sick to search for a job might miss handing in a sick note to the caseworker. Once they receive a vacancy referral, they may inform their

\footnotetext{
${ }^{8}$ The maximum duration of an unemployment and an employment spell is restricted to 36 months. This corresponds to the maximum duration we observe in our data.
} 
caseworker about their illness. Although based on the data at hand it is not possible to fully reject this explanation, we argue that it is not very plausible that these effects explain a main part of our findings. First, the caseworkers emphasized that unemployed must report sick as soon as they are sick, and that every unemployed individual receives an information leaflet at the beginning of unemployment in which this rule is explicitly stated. Second, in our empirical specification sickness absence is defined as being sick for a period of at least 14 days. We argue that individuals who are sick for 14 days usually consult a medical doctor. In that case, handing in the sick note involves only little additional costs to the unemployed. Third, sending out an application to an assigned vacancy usually does not involve a lot of effort for unemployed job seekers, who are in general obliged to have prepared an updated $\mathrm{CV}$ and corresponding documents for potential applications. Therefore, it seems to be plausible that in most of the times unemployed job seekers who are sick are still able to send out an application. This implies that reporting sick after the receipt of a vacancy referral might often be motivated by an avoidance strategy. Overall, we do not believe that late reporting is the driving force of the VR effect on sickness absence, although it might explain a (small) part of the effects.

Our findings suggest a strong and positive impact of receiving a job vacancy referral on the probability of finding a job. These results have to be interpreted with caution. While the assumption of no spillovers between treated and non.-treated seems to be not very strong in the case of imposed sanctions - only a very small number of unemployed job seekers are sanctioned during their period of unemployment - this is more problematic for VRs. Since the share of unemployed workers receiving a VR is relatively high - on average around $19 \%$ per month - it seems to be plausible that the increased transition rate from unemployment to employment for treated individuals might go along with a decreased transition rate for the non-treated job seekers. For example, Gautier, Muller, van der Klaauw, Rosholm, and Svarer (2012) provide corresponding evidence for an activation program in Denmark; they find that the nonparticipants in the regions where the program has been introduced find jobs slower relative to workers in other regions. While the analysis of spillover and general equilibrium effects goes beyond the focus of this paper, we have to keep in mind that the positive treatment effects might go along with negative spillover effects for non-treated individuals. 


\section{Conclusions}

In this paper, we analyze the effects of sanctions and vacancy referrals on unemployment duration and job quality. To evaluate sanction effects and the impact of receiving vacancy referrals, we take the endogenous probability of reporting sick into account. We use administrative register data on vacancy referrals by case workers, and we estimate multi-spell duration models with correlated selection on unobserved characteristics.

Receiving a vacancy referral has different impacts on the job search process of unemployed workers in Germany. On the one hand, it strongly increases the probability of finding a job and therewith helps the job seeker to avoid a period of long unemployment. On the other hand, this form of job search assistance leads to jobs of lower quality than jobs found via private search; the jobs found after the receipt of a VR have a lower wage and the probability of reentering unemployment is higher. However, simulations show that the overall impact of receiving VRs on the job stability almost zero. The indirect effect of a VR on the expected unemployment duration - a longer unemployment duration goes along with less stable jobs - cancels out the negative direct effect. For daily wages, the overall effect stays negative.

While the sanction rate of unemployed workers in Germany is quite small during our observation period, our results suggest a strong link between the imposition of a sanction and the receipt of a VR; most of the individuals who are sanctioned have received a VR before. This indicates that VRs are also used as a tool for monitoring the job search behavior of unemployed workers and that there exists a risk of being sanctioned when not applying to an assigned vacancy. In line with evidence for other countries, these imposed sanctions lead to an increased job finding probability of unemployed workers and the jobs taking up after being sanctioned go along with significantly reduced wages and a higher probability of reentering unemployment. These effects can be observed mainly within the first three months after the imposition of a sanction. Once the unemployed job seekers receive the full benefit amount again (after three months), the previously imposed sanction has no significant impact on the job finding probability any more.

In the German unemployment insurance system, minimum requirements on search behavior do not apply during sickness absence. This implies that some individuals may try to avoid an application to an assigned vacancy and the risk of being sanctioned by reporting sick. Indeed, we observe a strong increase in the probability of reporting sick after the arrival of a vacancy referral, which can be interpreted as an avoidance strategy. Moreover, we find evidence that this avoidance strategy is 
changing with respect to elapsed unemployment duration. While we find a strong impact of receiving a VR on the probability of reporting sick at the beginning of an unemployment spell, this effect is becoming smaller the longer individuals are unemployed. This decline in the impact on reporting sick indicates that the avoidance of VRs becomes less attractive the longer job seekers are unemployed.

In this study, we are mainly interested in quantifying the causal effects of current policy measures on individual job search outcomes. While our results enhance our understanding of the impact of vacancy referrals and imposed sanctions on individual unemployment duration and job match quality, our reduced form analysis does not allow to predict individual behavior in counterfactual policy designs. For example, we cannot use our model estimates to predict the average unemployment duration in a world without vacancy referrals or in a world in which vacancy referrals are assigned to long-term unemployed only. Instead, our approach allows to simulate treatment effects in the current policy setting. In order to get more insights in the optimal policy design for job search assistance and monitoring, we would have to estimate the underlying structural parameters of the individual decision process. This goes beyond the scope of this paper, but it is an important and interesting topic for future research. 


\section{References}

Abbring, J. H., and G. J. van Den Berg (2003): "The Nonparametric Identification of Treatment Effects in Duration Models," Econometrica, 71(5), 1491-1517.

Aitkin, M. (1999): "A General Maximum Likelihood Analysis of Variance Components in Generalized Linear Models," Biometrics, 55(1), 117-128.

Arni, P., R. Lalive, and J. C. van Ours (2012): "How Effective Are Unemployment Benefit Sanctions? Looking Beyond Unemployment Exit," Journal of Applied Econometrics, forthcoming.

Bundesagentur Für ArBeit (2004): "Arbeitsmarkt 2003 - Amtliche Nachrichten der Arbeitsmarkt 2003," 52. Jahrgang. Sondernummer, 15. Juli, Nuremberg.

Caliendo, M., K. Tatsiramos, and A. Uhlendorff (2012): "Benefit Duration, Unemployment Duration and Job Match Quality: A Regression-Discontinuity Approach," Journal of Applied Econometrics, forthcoming.

Crepon, B., M. Ferracci, G. Jolivet, and G. J. van den Berg (2010): "Analyzing the Anticipation of Treatments Using Data on Notification Dates," IZA Discussion Paper, 5265.

DundLER, A. (2006): "Description of the person-related Variables from the Datasets IEBS, IABS and LIAB, Version 1.0 - handbook version 1.0.0.," FDZ Datenreport 04, Institute for Employment Research (IAB), Nuremberg.

Eberwein, C., J. C. Ham, And R. LaLonde (1997): "The Impact of Being Offered and Receiving Classroom Training on the Employment Histories of Disadvantaged Women: Evidence from Experimental Data," Review of Economic Studies, 64, 655-682.

Engström, P., P. Hesselius, and B. Holmlund (2012): "Vacancy Referrals, Job Search, and the Duration of Unemployment: A Randomized Experiment," Labour, fortcoming.

Gaure, S., K. Roed, And T. Zhang (2007): "Time and Causality: A Monte Carlo Assesment of the timing-of-events approach," Journal of Econometrics, 141, 1159-1195.

Gautier, P., P. Muller, B. van Der KlaAuw, M. Rosholm, and M. Svarer (2012): "Estimating Equilibrium Effects of Job Search Assistance," IZA Discussion Paper, 6748. 
Graversen, B. K., And J. van Ours (2008): "How to help unemployed find jobs quickly: Experimental evidence from a mandatory activation program," Journal of Public Economics, 92, 2020-2035.

Hall, C., and L. Hartman (2010): "Moral Hazard among the Sick and Unemployed: Evidence from a Swedish Social Insurance Reform," Empirical Economics, $39(1), 27-50$.

Ham, J. C., And R. LaLonde (1996): "The Effect of Sample Selection and Initial Conditions in Duration Models: Evidence from Experimental Data on Training," Econometrica, 64, 175-205.

Heckman, J., and S. Navarro (2007): "Dynamic Discrete Choice and Dynamic Treatment Effects," Journal of Econometrics, 136, 341-396.

Henningsen, M. (2008): "Benefit shifting: The Case of Sickness Insurance for the Unemployed," Labour Economics, 15(6), 1238-1269.

Hofmann, B. (2010): "Sick of Being Activated? Effects of job vacancy proposals on short-term sickness absence of unemployment insurance benefit recipients," mimeo.

Honore, B. (1993): "Identification Results for Duration Models with Multiple Spells," Review of Economic Studies, 60, 241-246.

Ichino, A., And R. T. Riphahn (2005): "The Effect of Employment Protection on Worker Effort: A Comparison of Absenteeism During and After Probation," Journal of the European Economic Association, 3(1), 120-143.

Konle-Seidl, R., W. Eichhorst, and M. Grienberger-Zingerle (2010): "Activation Policies in Germany: From Status Protection to Basic Income Support," German Policy Studies, 6, 59-100.

Lalive, R., J. C. van Ours, and J. Zweimüller (2005): "The Effect Of Benefit Sanctions On The Duration Of Unemployment," Journal of the European Economic Association, 3(6), 1386-1417.

Larsson, L. (2006): "Sick of Being Unemployed? Interactions between Unemployment and Sickness Insurance," Scandinavian Journal of Economics, 108(1), 97113.

Markussen, S., K. Roed, O. J. Rogeberg, and S. Gaure (2011): "The anatomy of absenteeism," Journal of Health Economics, 30, 277-292. 
Müller, K.-U., And F. Oschmiansky (2006): "Die Sanktionspolitik der Arbeitsagenturen nach den "Hart"-Reformen. Analyse der Wirkungen des "Ersten Gesetzes für moderne Dienstleistungen am Arbeitsmarkt," WZB Discussion Paper 116, Wissenschaftszentrum Berlin, Berlin.

Pollmann-Schult, M. (2005): "Fuehren verschärfte Zumutbarkeitsregels der Arbeitsvermittlung zu schnellerer Wiederbeschäftigung? - Empirische Analysen zur Wirkung der Neuregelung der Zumutbarkeitsbestimmungen im Jahr 1997," Zeitschrift für Sozialreform, 51(3), 315-336.

Ruhm, C. (2000): "Are recessions good for your health?," Quarterly Journal of Economics, 115, 617-650.

Skrondal, A., and S. Rabe-Hesketh (2009): "Prediction in multilevel generalized models," Journal of the Royal Statistical Society Series A, 172, 659-687.

VAn den Berg, G. J., And B. VAn Der KlaAuw (2006): "Counseling and monitoring of unemployed workers: theory and evidence from a controlled social experiment," International Economic Review, 47(895-936).

van den Berg, G. J., B. van der KlaAuw, and J. C. van Ours (2004): "Punitive Sanctions and the Transition Rate from Welfare to Work," Journal of Labor Economics, 22(1), 211-210.

VAn Den Berg, G. J., And J. Vikstroem (2012): "Monitoring Job Offer Decisions, Punishments, Exit to Work, and Job Quality," Scandinavian Journal of Economics, forthcoming.

VAN Der KlaAuw, B., And J. VAn Ours (2012): "Carrot and Stick: How ReEmployment Bonuses and Benefit Sanctions Affect Exit Rates From Welfare," Journal of Applied Econometrics, forthcoming.

Ziebarth, N., and M. Karlsson (2010): "A Natural Experiment on Sick Pay Cuts, Sickness Absence, and Labor Costs," Journal of Public Economics, 94, 11081122 . 


\section{$7 \quad$ Figures and Tables}

Figure 1: Empirical Transition Rates and Treatment Probabilities
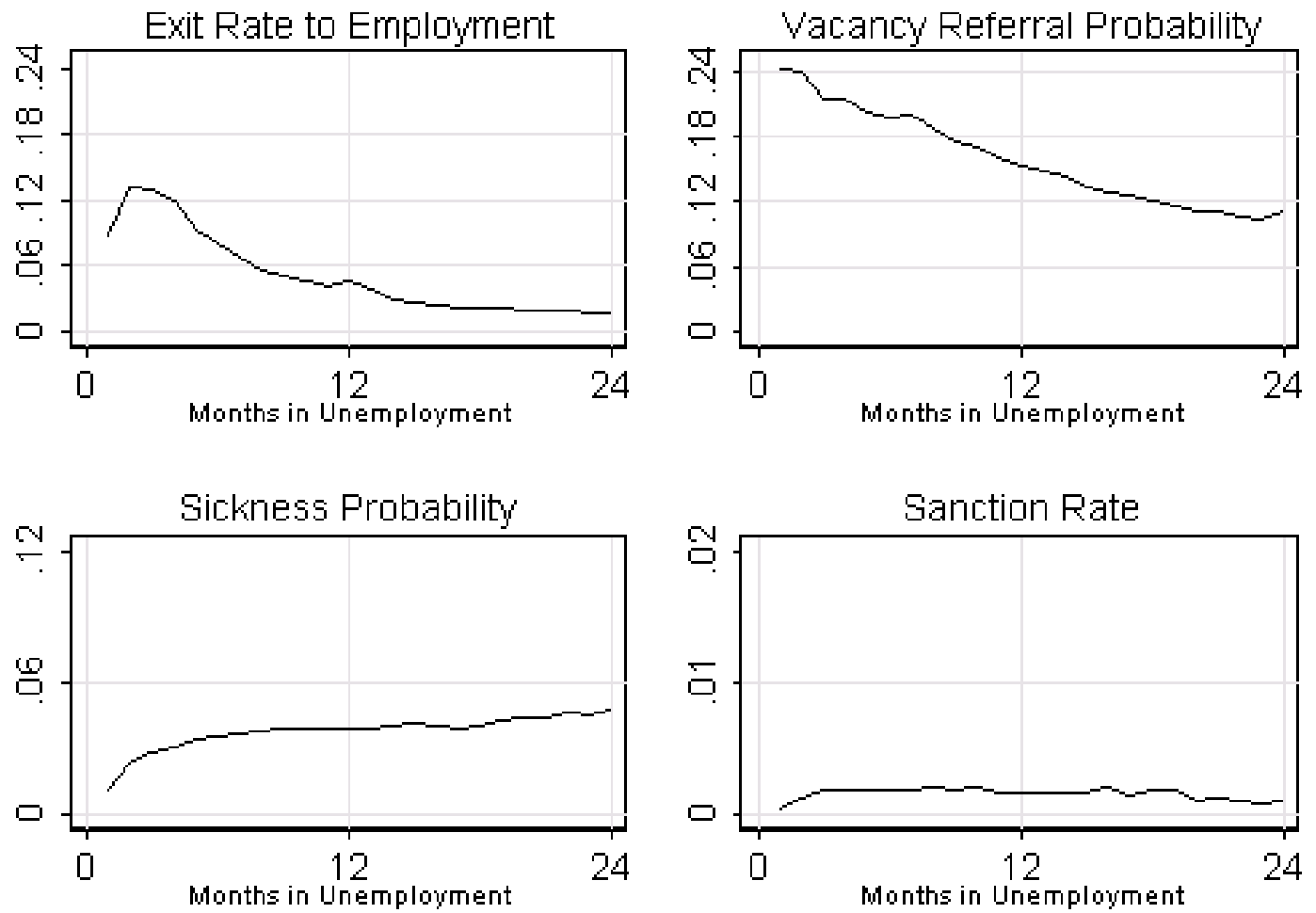

Notes: Graphs are based on 169,876 unemployment spells; number of individuals: 106,978 
Figure 2: Timing of Vacancy Referrals, Sanctions, and Transitions to Employment

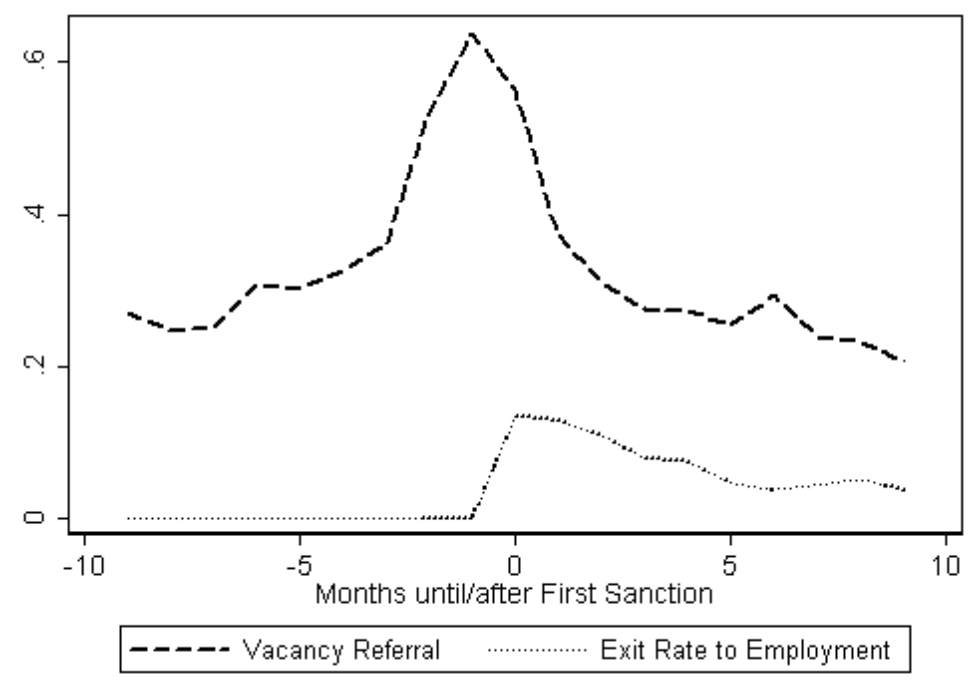

Notes: Month 0 refers to the month a sanction is imposed. Figure is based on individuals who have been sanctioned during their first spell of unemployment $(n=1,711)$. By construction, the job finding probability is zero before month 0 .

Figure 3: Timing of Vacancy Referrals, Sickness Absence, and Transitions to Employment

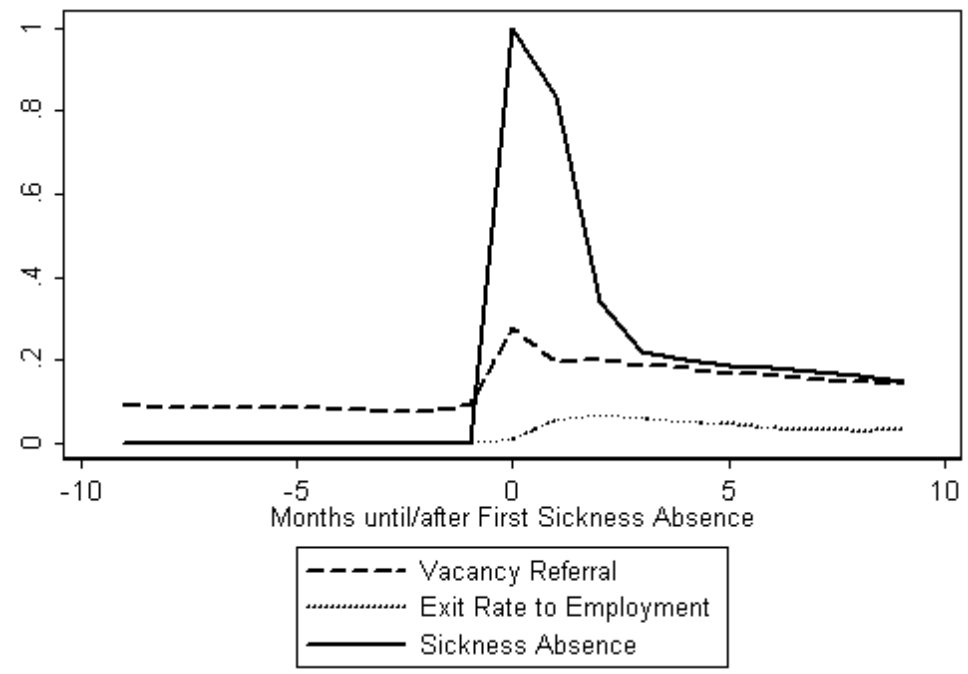

Notes: Month 0 refers to the first time an individual reports sick. Figure is based on individuals who reported sick at least once during their first spell of unemployment $(\mathrm{n}=11,233)$. By construction, the job finding probability is zero before month 0 . 
Figure 4: Simulated sickness probabilities

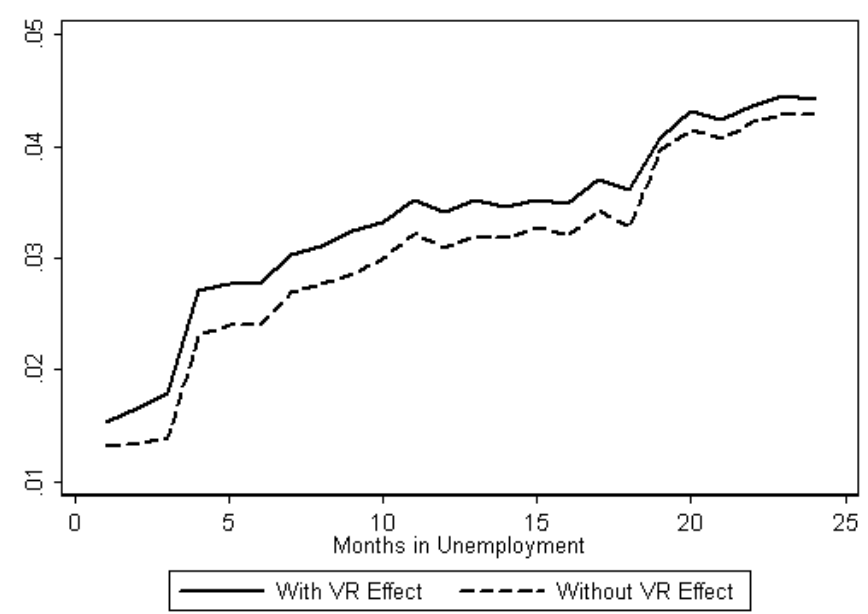

Notes: Simulations are based on the estimated coefficients and are performed for the average unemployed worker in our sample. Share 1: situation in which we allow for an effect of receiving a vacancy referral on the probability of reporting sick. Share 2: situation in which we set this effect to zero, i.e., we assume that workers do not react in their sickness absence on the arrival of a vacancy referral. 
Table 1: Number of observations and transitions

\begin{tabular}{|c|c|}
\hline \multicolumn{2}{|l|}{ Unemployment } \\
\hline No. months & $1,154,053$ \\
\hline No. spells & 169,876 \\
\hline$\%$ exits to employment & 54.7 \\
\hline$\% 1$ spell & 57.50 \\
\hline$\% 2$ spells & 29.12 \\
\hline$\% 3$ spells & 10.90 \\
\hline$\%>3$ spells & 2.47 \\
\hline \multicolumn{2}{|l|}{ Vacancy Referrals (VR) } \\
\hline No. VR arrivals & 223,837 \\
\hline$\%$ individuals received VR & 70.4 \\
\hline$\% 1 \mathrm{VR}$ & 36.18 \\
\hline$\% 2 \mathrm{VRs}$ & 21.76 \\
\hline$\% 3 \mathrm{VRs}$ & 13.54 \\
\hline$\%>3 \mathrm{VRs}$ & 28.52 \\
\hline \multicolumn{2}{|l|}{ Sanctions (S) } \\
\hline No. & 1,759 \\
\hline$\%$ unemployment spells with $\mathrm{S}$ & 1.0 \\
\hline$\%$ sanctioned individuals & 1.6 \\
\hline \multicolumn{2}{|l|}{ Sickness absence (SA) } \\
\hline No. months in SA & 35,770 \\
\hline$\%$ individuals in $\mathrm{SA}$ & 10.5 \\
\hline$\% 1$ month SA & 16.28 \\
\hline$\% 2$ months $\mathrm{SA}$ & 44.13 \\
\hline$\% 3$ months SA & 14.30 \\
\hline$\%>3$ months SA & 25.29 \\
\hline \multicolumn{2}{|l|}{ Employment } \\
\hline No. spells & 92,783 \\
\hline$\%$ exits to unemployment & 40.2 \\
\hline$\% 1$ spell & 73.32 \\
\hline$\% 2$ spells & 20.70 \\
\hline$\% 3$ spells & 5.25 \\
\hline$\%>3$ spells & 0.74 \\
\hline \multicolumn{2}{|c|}{$\begin{array}{l}\text { Notes: } \mathrm{n}=106,978 \text {; individuals might receive } \\
\text { more than one VR in a specific month. This } \\
\text { is not taken into account. Repeated sanctions } \\
\text { during one unemployment spell are ignored. }\end{array}$} \\
\hline
\end{tabular}


Table 2: Descriptive Statistics

\begin{tabular}{|c|c|c|}
\hline Sample & & \\
\hline \multicolumn{3}{|l|}{ Full Sample } \\
\hline Age & \multicolumn{2}{|c|}{$38.3(8.7)$} \\
\hline German $(\%)$ & \multicolumn{2}{|c|}{84.4} \\
\hline Married (\%) & \multicolumn{2}{|c|}{57.3} \\
\hline Child (\%) & \multicolumn{2}{|c|}{47.2} \\
\hline Medium secondary school (\%) & \multicolumn{2}{|c|}{18.4} \\
\hline Upper secondary school (\%) & \multicolumn{2}{|c|}{10.2} \\
\hline Vocational training (\%) & \multicolumn{2}{|c|}{59.4} \\
\hline Health restrictions (\%) & \multicolumn{2}{|c|}{16.3} \\
\hline Local unemployment rate (\%) & \multicolumn{2}{|c|}{$8.5(3.5)$} \\
\hline Local vacancy rate (\%) & \multicolumn{2}{|c|}{$14.9(9.7)$} \\
\hline Sanctioned & $Y e s$ & No \\
\hline Age & $35.0(7.6)$ & $38.4(8.7)$ \\
\hline German (\%) & 75.4 & 84.5 \\
\hline Married (\%) & 43.6 & 57.5 \\
\hline Child $(\%)$ & 41.6 & 47.3 \\
\hline Medium secondary school (\%) & 16.1 & 18.4 \\
\hline Upper secondary school (\%) & 6.0 & 10.3 \\
\hline Vocational training (\%) & 49.2 & 59.6 \\
\hline Health restrictions $(\%)$ & 11.6 & 16.4 \\
\hline Local unemployment rate (\%) & $7.8(2.9)$ & $8.5(3.5)$ \\
\hline Local vacancy rate $(\%)$ & $16.6(10.2)$ & $14.9(9.7)$ \\
\hline Sick & Yes & No \\
\hline Age & $40.3(8.8)$ & $38.1(8.7)$ \\
\hline German (\%) & 82.1 & 84.6 \\
\hline Married (\%) & 58.6 & 57.1 \\
\hline Child (\%) & 48.2 & 47.1 \\
\hline Medium secondary school (\%) & 13.2 & 19.0 \\
\hline Upper secondary school (\%) & 5.5 & 10.8 \\
\hline Vocational training $(\%)$ & 54.5 & 60.0 \\
\hline Health restrictions (\%) & 26.5 & 15.1 \\
\hline Local unemployment rate (\%) & $8.5(3.5)$ & $8.5(3.4)$ \\
\hline Local vacancy rate $(\%)$ & $15.0(9.9)$ & $14.9(9.6)$ \\
\hline$V R$ received & Yes & No \\
\hline Age & $37.8(8.4)$ & $39.5(9.4)$ \\
\hline German $(\%)$ & 83.8 & 85.8 \\
\hline Married (\%) & 56.0 & 60.5 \\
\hline Child (\%) & 47.8 & 45.8 \\
\hline Medium secondary school (\%) & 18.5 & 17.9 \\
\hline Upper secondary school (\%) & 9.8 & 11.2 \\
\hline Vocational training (\%) & 59.1 & 60.3 \\
\hline Health restrictions (\%) & 15.1 & 19.5 \\
\hline Local unemployment rate $(\%)$ & $8.4(3.4)$ & $8.6(3.6)$ \\
\hline Local vacancy rate (\%) & $15.0(9.7)$ & $14.6(9.6)$ \\
\hline
\end{tabular}

Notes: Characteristics are measured in first month of first unemployment spell. Standard deviations in parentheses. The vacancy rate is defined as the number of vacancies divided by the number of job seekers. The different subsamples refer to whether the job seekers have been sanctioned, have been sick and have received a VR, respectively, at least once during their first unemployment spell. 
Table 3: Effects of Vacancy Referrals and Sanctions (Model I)

\begin{tabular}{lccccc}
\hline \hline & Sanction & $\begin{array}{c}\text { Sickness } \\
\text { absence }\end{array}$ & $\begin{array}{c}\text { Exit to } \\
\text { employment }\end{array}$ & $\begin{array}{c}\text { Exit from } \\
\text { employment }\end{array}$ & Log(wage) \\
\hline Vacancy Referral & $1.8340^{* * *}$ & $0.4669^{* * *}$ & $0.5631^{* * *}$ & $0.0671^{* * *}$ & $-0.0260^{* * *}$ \\
& $(0.0669)$ & $(0.0114)$ & $(0.0086)$ & $(0.0128)$ & $(0.0024)$ \\
Sanction & - & & $0.2497^{* * *}$ & $0.2364^{* * *}$ & $-0.1083^{* * *}$ \\
& - & & $(0.0371)$ & $(0.0571)$ & $(0.0090)$ \\
\hline \hline
\end{tabular}

Notes: Standard errors in parentheses. ${ }^{* * *},{ }^{* *}, *$ indicate significance at $1 \%, 5 \%$ and $10 \%$ respectively. $\mathrm{n}=106,978 . \mathrm{M}=6$. LogLikelihood=-1135,843.16.

Table 4: Time-Varying Effects of Sanctions (Model II)

\begin{tabular}{lccc}
\hline \hline & Exit to & Exit from & Log(wage) \\
& employment & employment & \\
\hline Sanction $\left(t_{u}-t_{s}<3\right)$ & $0.3340^{* * *}$ & $0.2640^{* * *}$ & $-0.1414^{* * *}$ \\
& $(0.0461)$ & $(0.0668)$ & $(0.0107)$ \\
Sanction $\left(t_{u}-t_{s} \geq 3\right)$ & 0.0872 & 0.1458 & $-0.0447^{* * *}$ \\
& $(0.0652)$ & $(0.1075)$ & $(0.0166)$ \\
\hline \hline
\end{tabular}

Notes: Standard errors in parentheses. ${ }^{* * *}, * *, *$ indicate significance at $1 \%, 5 \%$ and $10 \%$ respectively. $\mathrm{n}=106,978 . t_{u}$ : month of unemployment; $t_{s}$ : month of the imposition of a sanction. $\mathrm{M}=6$. LogLikelihood=-1135,636.20.

Table 5: Heterogenous Effects of Vacancy Referrals (Model II)

\begin{tabular}{lccccc}
\hline \hline $\begin{array}{l}\text { Month of } \\
\text { Vacancy } \\
\text { Referral }\end{array}$ & Sanction & $\begin{array}{c}\text { Sickness } \\
\text { absence }\end{array}$ & $\begin{array}{c}\text { Exit to } \\
\text { employment }\end{array}$ & $\begin{array}{c}\text { Exit from } \\
\text { employment }\end{array}$ & Log(wage) \\
\hline $1 \leq t_{u} \leq 3$ & $2.0426^{* * *}$ & $0.6905^{* * *}$ & $0.5805^{* * *}$ & $0.0436^{* * *}$ & $-0.0385^{* * *}$ \\
& $(0.1390)$ & $(0.0209)$ & $(0.0111)$ & $(0.0167)$ & $(0.0031)$ \\
$4 \leq t_{u} \leq 6$ & $1.6240^{* * *}$ & $0.4995^{* * *}$ & $0.4529^{* * *}$ & -0.0039 & $-0.0159^{* * *}$ \\
& $(0.1245)$ & $(0.0231)$ & $(0.0148)$ & $(0.0214)$ & $(0.0041)$ \\
$7 \leq t_{u} \leq 9$ & $1.8038^{* * *}$ & $0.4193^{* * *}$ & $0.6171^{* * *}$ & $0.2223^{* * *}$ & $-0.0136^{* *}$ \\
& $(0.1586)$ & $(0.0278)$ & $(0.0225)$ & $(0.0324)$ & $(0.0059)$ \\
$10 \leq t_{u} \leq 12$ & $1.9962^{* * *}$ & $0.3589^{* * *}$ & $0.6794^{* * *}$ & $0.2072^{* * *}$ & 0.0011 \\
& $(0.1991)$ & $(0.0335)$ & $(0.0312)$ & $(0.0459)$ & $(0.0077)$ \\
$13 \leq t_{u} \leq 18$ & $1.6794^{* * *}$ & $0.3311^{* * *}$ & $0.7277^{* * *}$ & $0.2566^{* * *}$ & 0.0089 \\
& $(0.1618)$ & $(0.0310)$ & $(0.0364)$ & $(0.0545)$ & $(0.0094)$ \\
$19 \leq t_{u} \leq 36$ & $1.9801^{* * *}$ & $0.1166^{* * *}$ & $0.5543^{* * *}$ & $0.2523^{* * *}$ & 0.0096 \\
& $(0.1950)$ & $(0.0325)$ & $(0.0531)$ & $(0.0893)$ & $(0.0143)$ \\
\hline \hline
\end{tabular}

Notes: Standard errors in parentheses. ${ }^{* * *}, * *, *$ indicate significance at $1 \%$, $5 \%$ and $10 \%$ respectively. $t_{u}$ : month of unemployment. $\mathrm{n}=106,978 . \mathrm{M}=6$. LogLikelihood=-1135,636.20. 
Table 6: Simulated Durations and Initial Daily Wages

\begin{tabular}{|c|c|c|c|}
\hline & $\begin{array}{c}(\mathrm{i}) \\
\text { Standard } \\
\text { Treatment }\end{array}$ & $\begin{array}{l}\text { (ii) } \\
\text { No Vancancy } \\
\text { Referral }\end{array}$ & $\begin{array}{c}\text { (iii) } \\
\text { No Vancancy } \\
\text { Referral in months 1-3 }\end{array}$ \\
\hline Unemployment Duration & $\begin{array}{l}14.39 \\
(0.05)\end{array}$ & $\begin{array}{l}16.70 \\
(0.07)\end{array}$ & $\begin{array}{l}15.05 \\
(0.05)\end{array}$ \\
\hline Wages & $\begin{array}{l}55.00 \\
(0.15)\end{array}$ & $\begin{array}{c}55.68 \\
(0.26)\end{array}$ & $\begin{array}{c}55.93 \\
(0.17)\end{array}$ \\
\hline Employment Duration & $\begin{array}{c}28.42 \\
(0.07)\end{array}$ & $\begin{array}{c}28.57 \\
(0.08)\end{array}$ & $\begin{array}{c}28.38 \\
(0.07)\end{array}$ \\
\hline
\end{tabular}

Note: The simulations are based on Model II allowing for treatment effect heterogeneity with respect to elapsed unemployment duration. All simulations are performed for the average individual in our sample with respect to observed characteristics. Standard treatment implies that individuals have a positive probability of receiving a VR at every point in time. In scenario (ii) this probability is set to zero in all periods. In scenario (iii) this probability is zero in the first three months of unemployment. Standard errors are computed using parametric bootstrap based on 250 draws from the covariance matrix of the estimated parameters. 
A Appendix 


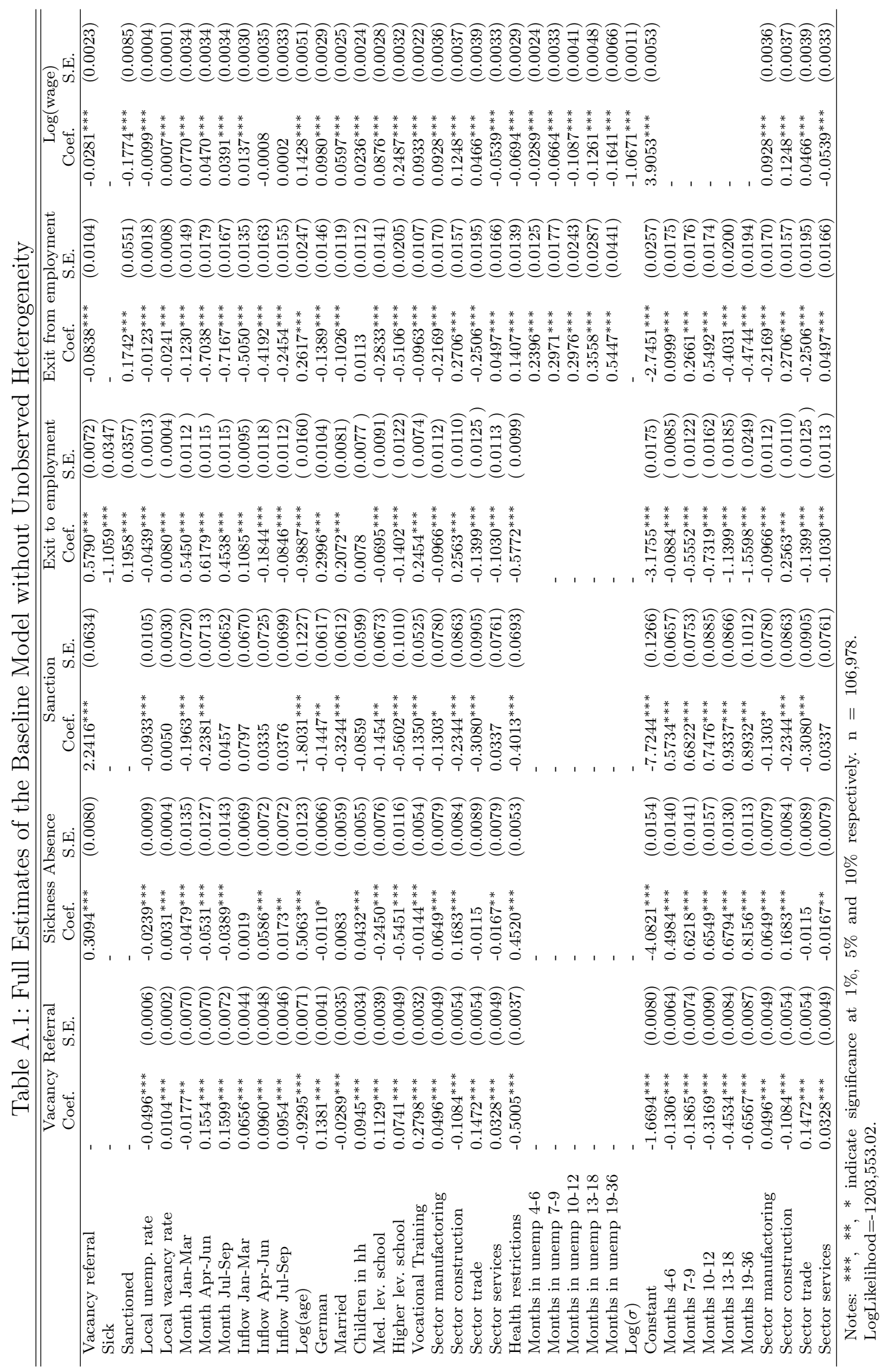




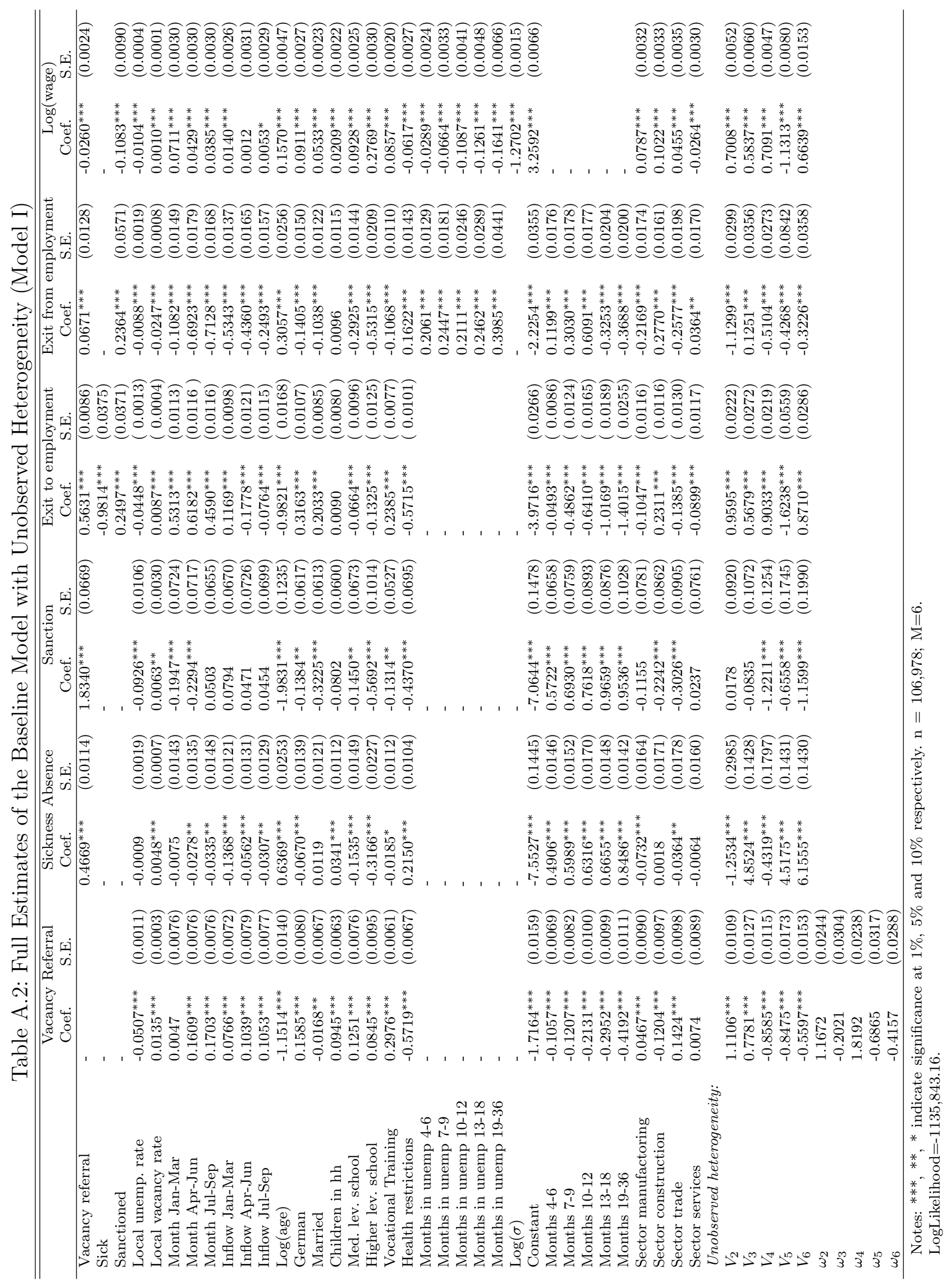


Table A.3: Correlation Matrix (Model I)

\begin{tabular}{lcccccc}
\hline \hline & $\begin{array}{c}\text { Exit to } \\
\text { employment }\end{array}$ & Sanction & $\begin{array}{c}\text { Sickness } \\
\text { absence }\end{array}$ & $\begin{array}{c}\text { Vacancy } \\
\text { referral }\end{array}$ & $\begin{array}{c}\text { Exit from } \\
\text { employment }\end{array}$ & Log(wage) \\
\hline Exit to & 1 & $-0.1729^{* * *}$ & $-0.4655^{* * *}$ & 0.1261 & $-0.4055^{* * *}$ & $0.9931^{* * *}$ \\
employment & & $(0.0529)$ & $(0.0124)$ & $(0.0111)$ & $(0.0392)$ & $(0.0012)$ \\
Sanction & $-0.1729^{* * *}$ & 1 & -0.0699 & $0.9339^{* * *}$ & $-0.2930^{* * *}$ & $-0.2066^{* * *}$ \\
& $(0.0529)$ & & $(0.0714)$ & $(0.0164)$ & $(0.0436)$ & $(0.0519)$ \\
Sickness & $-0.4655^{* * *}$ & -0.0699 & 1 & $-0.1381^{* * *}$ & $0.6116^{* * *}$ & $-0.4011^{* * *}$ \\
absence & $(0.0124$ & $(0.0714)$ & & $(0.0476)$ & $(0.0399)$ & $(0.0107)$ \\
Vacancy & $0.1261^{* * *}$ & $0.9339^{* * *}$ & $-0.1381^{* * *}$ & 1 & $-0.5013^{* * *}$ & $0.0964^{* * *}$ \\
referral & $(0.0111)$ & $(0.0164)$ & $(0.0476)$ & & $(0.0189)$ & $(0.0054)$ \\
Exit from & $-0.4055^{* * *}$ & $-0.2930^{* * *}$ & $0.6116^{* * *}$ & $-0.5013^{* * *}$ & 1 & $-0.3370^{* * *}$ \\
employment & $(0.0392)$ & $(0.0436)$ & $(0.0399)$ & $(0.0189)$ & & $(0.0386)$ \\
Log(wage) & $0.9931^{* * *}$ & $-0.2066^{* * *}$ & $-0.4011^{* * *}$ & $0.0964^{* * *}$ & $-0.3370^{* * *}$ & 1 \\
& $(0.0012)$ & $(0.0519)$ & $(0.0107)$ & $(0.0054)$ & $(0.0386)$ & \\
\hline
\end{tabular}

Notes: Standard errors in parentheses. ${ }^{* * *},{ }^{* *}, *$ indicate significance at $1 \%, 5 \%$ and $10 \%$ respectively. The correlations are based on the coefficients estimated for the distribution of the unobserved heterogeneity reported in Table A.2. 


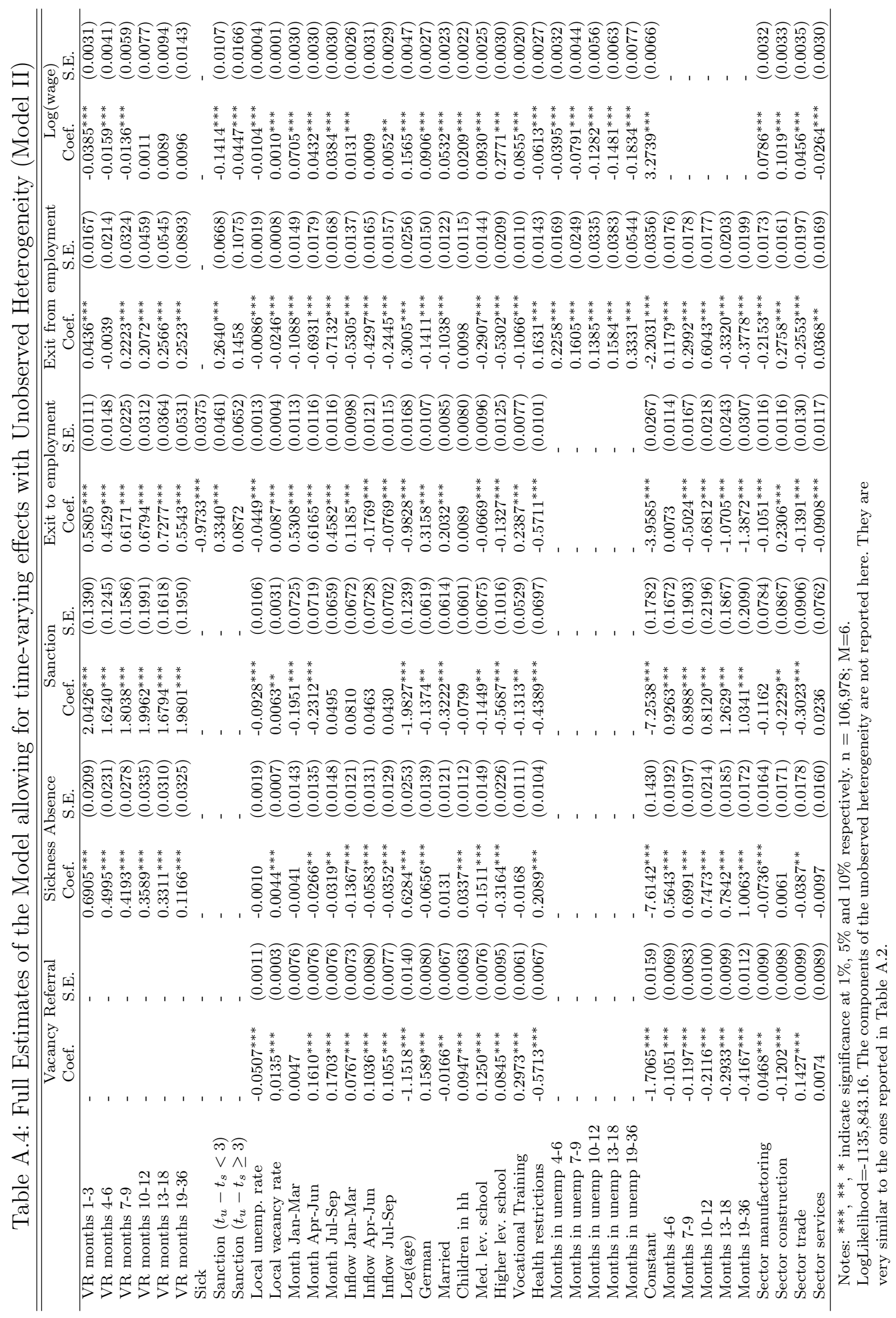

